\title{
Tosse: neurofisiologia, métodos de pesquisa, terapia farmacológica e fonoaudiológica
}

\section{Cough: neurophysiology, methods of research, pharmacological therapy and phonoaudiology}

\author{
Aracy Pereira Silveira Balbani ${ }^{1}$ \\ 1) Doutora em Medicina. Médica Otorrinolaringologista. \\ Instituição: Consultório particular da Autora. \\ Tatui - SP - Brasil. \\ Endereço para correspondência: Aracy P. S. Balbani - Rua Capitão Lisboa, 715 - Tatuí / SP - Brasil CEP: 18270-070 - Telefone: (+55 15) 3259-1152 - E-mail: \\ a_balbani@hotmail.com \\ Artigo recebido em 13 de Março de 2011. Artigo aprovado em 25 de Junho de 2011.
}

\section{RESUMO}

Introdução: A tosse é o sintoma respiratório mais comum em crianças e adultos.

Objetivo: Apresentar uma revisão sobre a neurofisiologia e os métodos para estudo do reflexo da tosse, bem como a farmacoterapia e terapia fonoaudiológica da tosse, baseada nos trabalhos publicados entre 2005 e 2010 e indexados nas bases Medline, Lilacs e Biblioteca Cochrane sob os unitermos "tosse" ou "antitussígenos".

Síntese dos dados: O reflexo da tosse envolve ativação de múltiplos receptores vagais nas vias aéreas e de projeções neurais do núcleo do trato solitário para outras estruturas do sistema nervoso central. Técnicas experimentais permitem estudar o reflexo da tosse ao nível celular e molecular para desenvolver novos agentes antitussígenos. Não há evidências de que antitussígenos isentos de prescrição médica tenham eficácia superior à do placebo para o alívio da tosse. A terapia fonoaudiológica pode beneficiar pacientes com tosse crônica refratária ao tratamento farmacológico, sobretudo quando coexiste movimento paradoxal das pregas vocais.

Comentários Finais: A abordagem multidisciplinar tem papel fundamental no diagnóstico etiológico e tratamento da tosse. O otorrinolaringologista deve informar os pacientes sobre os riscos dos antitussígenos de venda livre a fim de prevenir intoxicações e efeitos adversos, especialmente em crianças. Palavras-chave: antitussígenos, codeína, dextrometorfano, expectorantes, tosse.

\section{SUMMARY}

Introduction: The cough is the more common respiratory symptom in children and adults.

Objective: To present a revision on the neurophysiology and the methods for study of the consequence of the cough, as well as the pharmacotherapy and phonoaudiology therapy of the cough, based on the works published between 2005 and 2010 and indexed in the bases Medline, Lilacs and Library Cochrane under them to keywords "cough" or "anti-cough". Synthesis of the data: The consequence of the cough involves activation of receiving multiples becomes vacant in the aerial ways and of neural projections of the nucleus of the solitary treatment for other structures of the central nervous system. Experimental techniques allow studying the consequence of the cough to the cellular and molecular level to develop new anti-cough agents. It does not have evidences of that anticough exempt of medical lapsing they have superior effectiveness to the one of placebo for the relief of the cough. The phonoaudiology therapy can benefit patients with refractory chronic cough to the pharmacological treatment, over all when paradoxical movement of the vocal folds coexists.

Final Comments: The boarding to multidiscipline has basic paper in the etiological diagnosis and treatment of the cough. The otolaryngologist must inform the patients on the risks of the anti-cough of free sales in order to prevent adverse poisonings and effect, especially in children.

Keyword: anti-cough, codeine, dextromethorpha, expectorants, cough. 


\section{INTRODUÇÃO}

A tosse é um mecanismo de proteção das vias aéreas e também o sintoma respiratório mais comum em crianças e adultos. Pode decorrer de inúmeras causas infecciosas (Tabela 1) e não infecciosas (Tabela 2), ser caracterizada como seca ou produtiva, e classificada, de acordo com a duração, em aguda (menos de 3 semanas), subaguda (3-8 semanas) ou crônica (mais de 8 semanas) $(1,2)$.

Os paroxismos de tosse podem prejudicar a qualidade de vida do paciente por interferirem no sono, provocarem disfonia, vômitos, cefaleia ou incontinência urinária.

Antitussígenos e mucolíticos - muitos dos quais são isentos de prescrição médica, estão entre os medicamentos mais consumidos no mundo. Eles oferecem risco de efeitos adversos e intoxicação, sobretudo na infância. Levantamento feito em 63 pronto-socorros norteamericanos revelou que $5,7 \%$ das intoxicações em menores de 12 anos foram provocadas por antitussígenos e antigripais, com predomínio dos casos (64\%) em crianças de dois a cinco anos de idade (3).

A toxicidade dos antitussígenos isentos de prescrição e os dados inconclusivos de sua eficácia clínica (4) levaram as autoridades de saúde do Canadá a contraindicálos aos menores de seis anos e adotarem medidas de segurança adicionais: advertência em bula sobre os cuidados no uso por crianças de 6 a 12 anos e padronização das embalagens (frasco à prova de abertura pela criança, acompanhado de copo dosador) (5). No Brasil, consta em bula a advertência de que antitussígenos não devem ser utilizados em crianças menores de dois anos de idade, e as indústrias farmacêuticas não estão obrigadas a utilizar embalagens à prova de manuseio por crianças.

Tabela I. Causas infecciosas de tosse.

\begin{tabular}{|c|c|c|}
\hline & & Exemplos de agentes etiológicos \\
\hline \multirow[t]{5}{*}{ Vírus } & Resfriadocomum & adenovírus, coronavírus, enterovírus, parainfluenza \\
\hline & Influenza(gripe) & vírus influenza $A$ e B \\
\hline & Bronquiolite & vírus sincicial respiratório(VSR) \\
\hline & Traqueobronquite aguda & vírus influenza, VSR \\
\hline & Hantavirose & vírus Juquitiba, Araraquara, Castelo dos Sonhos, Laguna Negra, Anajatuba \\
\hline \multirow{4}{*}{ Bactérias } & Coqueluche & Bordetellapertussis \\
\hline & Traqueobronquiteaguda & Mycoplasmapneumoniae \\
\hline & $\begin{array}{l}\text { Rinossinusites (síndrome da tosse da } \\
\text { via aéreasuperior) }\end{array}$ & $\begin{array}{l}\text { Streptococcuspneumoniae } \\
\text { Haemophilus influenzae } \\
\text { Moraxellacatarrhalis }\end{array}$ \\
\hline & $\begin{array}{l}\text { Pneumonias bacterianas } \\
\text { Micobacteriosestípicas e atípicas }\end{array}$ & $\begin{array}{l}\text { Streptococcuspneumoniae } \\
\text { Mycoplasmapneumoniae } \\
\text { Chlamydophilapneumoniae } \\
\text { Haemophilusinfluenzae } \\
\text { Mycobateriumtuberculosis }\end{array}$ \\
\hline Parasitas & $\begin{array}{l}\text { Eosinofilia pulmonar parasitária } \\
\text { (Síndrome de Loeffler) } \\
\text { Esquistossomose pulmonar crônica } \\
\text { Larva migrans visceral } \\
\text { Singamose }\end{array}$ & $\begin{array}{l}\text { Ascaris/umbricoides } \\
\text { Ancylostomaduodenale } \\
\text { Strongyloidesstercoralis } \\
\text { Schistosomamansoni } \\
\text { Toxocara canis, Toxocara cati } \\
\text { Syngamuslaryngeus }\end{array}$ \\
\hline Protozoário & Leishmaniose visceral & Leishmaniachagasi \\
\hline Fungos & $\begin{array}{l}\text { Aspergilose } \\
\text { Blastomicose } \\
\text { Criptococose } \\
\text { Histoplasmose } \\
\text { Paracoccidiodomicose } \\
\text { Pneumocistose }\end{array}$ & $\begin{array}{l}\text { Aspergillusspp } \\
\text { Blastomycesdermatitidis } \\
\text { Cryptococcusneoformans } \\
\text { Histoplasmacapsulatum } \\
\text { Paracoccidioides brasiliensis } \\
\text { Pneumocystisjiroveci }\end{array}$ \\
\hline
\end{tabular}


Tabela 2. Causas não infecciosas de tosse.

Medicamentos

Doenças cardiovasculares

Refluxo gastroesofágico

Aspiração de corpo estranho

Neoplasias

Asma

Doença pulmonarobstrutiva crônica

Inalação de irritantes

Pneumoconioses

Outras

\author{
Inibidores da enzima conversora da angiotensina \\ Betabloqueadores \\ Interferon peguilado (molde brônquico) \\ Metotrexato(pneumonite) \\ Edemapulmonar \\ Embolia pulmonar
}

Nota:

Variante da asma comtosse ${ }^{(a)}$

Gás mostarda, formaldeído

Silicose

Tosse pós-infecciosaTosse atópica ${ }^{(b)}$ Tosse psicogênica

(a) Variante comtosse da asma: tosse crônica responsiva ao uso de broncodilatador ou corticosteroide inalatório/sistêmico.

(b) Tosse atópica: tosse crônica sem obstrução reversível do fluxo aéreo nem hiperresponsividade brônquica, na qual há confirmação de atopia (eosinofilia sanguínea ou no escarro, ou elevação da lgE sérica específica, ou teste cutâneo de hipersensibilidade imediata positivo. Refratária à terapia combroncodilatador e responsiva ao uso de corticosteroide inalatório ou anti-histamínico HI .

Em 2007, um fabricante retirou do mercado mundial, preventivamente, antitussígenos contendo cloridrato de clobutinol, pelo risco de prolongarem o intervalo QT e induzirem arritmia cardíaca (torsades de pointes) (6). Contudo, este princípio ativo ainda é comercializado por outras empresas ( 7 ).

O otorrinolaringologista costuma atender casos de tosse acompanhada de irritação faríngea ou desencadeada por contato com perfumes e outros inalantes, variações de temperatura e atos de falar, rir ou cantar. Frequentemente o clínico e o pediatra encaminham pacientes para que o especialista investigue a síndrome da tosse da via aérea superior, antes denominada gotejamento pós-nasal.

Por tudo isso, é necessário que o otorrino conheça a neurofisiologia da tosse, os métodos científicos para seu estudo e o tratamento farmacológico e fonoaudiológico para alívio do sintoma, temas abordados nesta revisão.

\section{REVISÃO DA LITERATURA}

Foram pesquisados para esta revisão não sistemática os trabalhos originais, de revisão, metanálise e relatos de caso publicados entre 2005 e 2010 e indexados nas bases Medline, Lilacs e Biblioteca Cochrane sob os unitermos "tosse" ou "antitussígenos".

\section{Neurofisiologia da tosse}

\section{Componentes periféricos}

O arco reflexo da tosse é iniciado no epitélio respiratório, diafragma, pericárdio, pleura, peritônio ou esôfago através do estímulo de mecanoceptores, nociceptores (quimiorreceptores) ou fibras Aä aferentes vagais (1). Em $2,3 \%-4,2 \%$ da população o reflexo pode ser evocado também pela palpação do meato auditivo externo - mais comumente da sua parede póstero-inferior, em uma ou ambas as orelhas -, por estímulo do ramo auricular do nervo vago (nervo de Arnold) $(8,9)$.

Em animais de experimentação, a secção bilateral do nervo laríngeo superior não altera o reflexo da tosse. A secção bilateral do nervo laríngeo recorrente abole a tosse provocada por estímulo mecânico ou elétrico da mucosa da laringe e porção superior da traqueia, mas não interfere no reflexo provocado pela inalação de vapor ácido.

Os mecanoceptores de baixo limiar respondem a estímulos mecânicos. Os receptores pulmonares de distensão (slowlyadapting stretch receptors-SARs e rapidlyadapting stretch receptors - RARs) são ativados fisiologicamente pela variação do volume pulmonar durante a respiração, enquanto os mecanossensores de tensão esofágicos são estimulados pela deglutição. Em condições patológicas, o edema da mucosa ou a broncoconstrição podem ativá-los. 
Tais receptores têm pequena sensibilidade a estímulos químicos (ácidos).

Os nociceptores ou quimiorreceptores respondem a estímulos químicos (capsaicina, bradicinina, prostaglandinas, ácidos), calor (temperatura acima de $42^{\circ} \mathrm{C}$ ) e alguns estímulos mecânicos extremos.

As fibras mielinizadas de adaptação rápida $\mathrm{A} \delta$, denominadas receptores de tosse, têm papel importante na defesa das vias aéreas, pois são muito sensíveis ao contato de líquidos ou partículas com a mucosa da laringe, traqueia e brônquios principais. Possuem características fisiológicas distintas das dos RARs e SARs, não são ativadas pela capsaicina ou bradicinina (10) e se acredita que sua função principal seja a regulação do reflexo da tosse evocado nas vias aéreas extrapulmonares.

As fibras não mielinizadas do tipo $C$ são os nociceptores vagais mais numerosos nos brônquios e pulmões (11) e as responsáveis pelo incômodo do impulso para tossir. Expressam vários canais iônicos de membrana, entre os quais os transient receptor potential vanilloid (TRPV) 1 a 4 - numerosos também na mucosa laríngea (12) -, e o transient receptor potential ankyrin-1 (TRPA-1), ativado diretamente por irritantes químicos (10) como a alicina da cebola e do alho, os isotiocianatos da mostarda e o formaldeído (13).

O antitussígeno de ação periférica ideal deveria inibir seletivamente as fibras $\mathrm{C}$, para abolir os paroxismos patológicos de tosse sem prejudicar o mecanismo fisiológico de defesa das fibras $A \delta$ contra aspiração. Isso poderia ocorrer pelo uso de: 1) um antagonista dos canais iônicos TRPV ou TRPA-1, ou 2) de um medicamento similar aos anestésicos locais, capaz de bloquear especificamente um canal de sódio regulado por voltagem e, assim, inibir o potencial de ação nas fibras C (10). As atuais linhas de pesquisa de novos antitussígenos testam moléculas com essas ações.

\section{Componentes centrais}

As vias aferentes da tosse convergem para o núcleo do trato solitário no tronco encefálico, ponto principal da regulação do reflexo. De lá partem múltiplas projeções neurais para: a formação reticular, núcleo ambíguo, substância cinzenta periaquedutal e núcleo dorsal da rafe (14).

Nos modelos experimentais, a tosse provocada pela estimulação mecânica da traqueia é intensificada pela instilação de capsaicina na mucosa nasal ou esofágica, indicando que no tronco encefálico há integração entre as aferências sensitivas do nervo trigêmeo na mucosa nasal e as aferências vagais traqueobrônquicas e esofágicas $(15,16)$.
Este seria um dos mecanismos predisponentes à tosse nos pacientes com afecções nasossinusais (síndrome da tosse da via aérea superior) ou refluxo gastroesofágico.

O glutamato parece ser o principal neurotransmissor excitatório das vias centrais da tosse, enquanto as neurocicininas (substância $\mathrm{P}$, neurocininas A e B) seriam neuromoduladoras. Tem sido pesquisada a ação central antitussígena de antagonistas do receptor de neurocininas (17).

O reflexo sofre controle voluntário do córtex cerebral. A estimulação seletiva das fibras C com capsaicina em animais sob anestesia geral não evoca tosse $(16,17)$. Em humanos, o impulso para tossir geralmente precede o ato motor da tosse e pode ser suprimido voluntariamente (18). Em contrapartida, a tosse psicogênica, que responde por 3 a 10\% dos casos de tosse crônica na infância, pode ser provocada pelo paciente e se manifestar com ou sem tiques (motores ou vocais), cessando durante o sono (19).

As vias eferentes da tosse trafegam através dos nervos vago e frênico e dos motoneurônios espinhais até a musculatura expiratória, resultando na sequência característica de movimentos respiratórios já exaustivamente descrita na literatura $(1,2,7)$.

\section{Modulação do reflexo}

O reflexo de proteção das vias aéreas é um mecanismo dinâmico que acompanha o amadurecimento do sistema nervoso central (SNC) e sofre influência de fatores hormonais e neuro-humorais.

Nos mamíferos recém-nascidos, especialmente os prematuros, a presença de secreção, conteúdo gástrico ou outros líquidos nas vias aéreas superiores (VAS) resulta em movimentos de deglutição e fechamento da glote, apneia, bradicardia e redistribuição do fluxo sanguíneo para órgãos vitais. A ação das interleucinas no SNC sensibiliza o reflexo e prolonga as apneias (20), o que explicaria o maior risco de morte súbita nos neonatos com infecções das vias aéreas superiores (IVAS).

Em filhotes de porco observam-se mudanças bioquímicas e bioelétricas nos motoneurônios respiratórios no primeiro mês de vida. Gradativamente diminui a ocorrência de deglutição e apneia, e a tosse passa a ser o componente principal do reflexo protetor das vias aéreas, característica que se mantém na vida adulta $(20,21)$.

Em humanos a sensibilidade do reflexo da tosse é maior nas mulheres e em pacientes com IVAS ou variante com tosse da asma (asma tussigênica) (22). 
Há dados controversos sobre o efeito do tabagismo no limiar do reflexo da tosse. Alguns estudos mostram aumento do limiar em fumantes, talvez por ação central ou periférica da nicotina, ou pelo aumento da espessura da camada de muco respiratório, que dificultaria a ativação dos receptores vagais traqueobrônquicos. Esse fenômeno é reversível em poucas semanas, razão pela qual muitas pessoas se queixam de tossir mais após pararem de fumar. Porém, outros tabagistas padecem de tosse crônica possivelmente pelo processo inflamatório nas vias aéreas -, aliviada pela abstinência do cigarro (23).

A enzima conversora da angiotensina (ECA) degrada não apenas a angiotensina I, mas também a bradicinina, substância P e neurocininas, as quais sensibilizam fibras C. Por esse motivo, cerca de $20 \%$ dos pacientes que usam anti-hipertensivos inibidores da ECA têm tosse como efeito colateral $(1,24)$. O sintoma tende a desaparecer cerca de quatro semanas após a interrupção do uso do antihipertensivo (25).

\section{Métodos de Estudo da Tosse}

Embora tenham numerosos aferentes sensitivos nas vias aéreas, ratos e camundongos não apresentam o típico ato motor da tosse, dificultando sua avaliação. Assim, o porquinho-da-Índia é a espécie de pequeno porte mais utilizada em experimentos $(13,16)$.

Nos trabalhos experimentais a tosse pode ser provocada pela microestimulação elétrica direta do núcleo do trato solitárioapós descerebração (26), ou por estimulação mecânica/elétrica da mucosa das vias aéreas em animais conscientes ou sob anestesia geral.

Tanto nos trabalhos experimentais quanto nos clínicos podem ser empregados vários estímulos químicos ou agentes tussigenos: capsaicina, ácidos (cítrico, acético, tartárico) e nebulizaçãoultrassônica deágua destilada ("fog").

A capsaicina é o tussígeno mais utilizado, administrado em dose única ou em esquema dose-resposta. Provoca tosse imediatamente, motivo pelo qual se recomenda avaliar seu efeito nos 15 segundos após a nebulização. Geralmente o parâmetro analisado nos estudos doseresposta é a concentração de capsaicina capaz de provocar cinco ou mais atos motores de tosse. O método é considerado reprodutível e seguro em humanos, mas alguns indivíduos se queixam de irritação faríngea transitória após exposiçãoà capsaicina.

Oácido cítrico tem maior probabilidade de causar sensação de sufocação e ardor na faringe. A nebulização ultrassônica de água destilada é insuficiente para ativar o reflexo de tosse em até $20 \%$ das pessoas, mas pode induzir broncoespasmo sintomático em outras, o que reduz a reprodutibilidade e segurança do método.

Estudos da eficácia de antitussígenos podem sofrer o viés do efeito demulcente (estímulo à secreção de saliva e muco nas VAS pelos açúcares) do placebo formulado em xarope (22) ou da inibição voluntária da tosse.

Na pesquisa clínica, o uso de questionários (Burden of Cough Questionnaire, Cough Specific Quality of Life Questionnaire, Leicester Cough Questionnaire) é útil para avaliar o impacto da tosse na qualidade de vida do paciente (27).

\section{Terapia Farmacológica da Tosse}

\section{Antitussígenos de ação periférica}

A dropropizina e seu enantiômero levodropropizina reduzem a sensibilidade das fibras $\mathrm{C}$ vagais (28). No Brasil, várias de suas apresentações em xarope contêm açúcar e uma apresentação da dropropizina em pastilhas têm corante amarelo tartrazina, o que as contraindica, respectivamente, para diabéticos e pessoas com intolerância ao ácido acetilsalicílico.

\section{Antitussígenos de ação central}

Odextrometorfano, o clobutinol e o fendizoato de cloperastina têm açãonão narcótica no tronco encefálico.

O dextrometorfano é agonista do receptor não opioide sigma-1 e antagonista do receptor N-metil-Daspartato (NMDA) do glutamato. Sua ação é similar à do ácido lisérgico (LSD), quetamina e psilocibina. O dextrometorfano é metabolizado pelo citocromo P450 (enzima CYP2D6), e indivíduos que o metabolizam lentamente são mais suscetíveis aos efeitos psicoativos, mesmo nas doses terapêuticas. O medicamento interage com inibidores da monoaminoxidase (MAO) e antidepressivos inibidores da recaptação da serotonina (29). Há registro de intoxicação fatal por dextrometorfano em criança (30).

O clobutinol retarda a repolarização ventricular e é arritmogênico (31). Já houve relato de anafilaxia pelo medicamento (32).

O fendizoato de cloperastina é sedativo da tosse e também temação periférica, dessensibilizando as aferências vagais traqueobrônquicas. Interage com inibidores da MAO.

Antitussígenos narcóticos (morfina e codeína) agem primariamente nos receptores opioides ì no núcleo do trato 
solitário no porquinho-da-Índia. Entretanto, a naloxona, antagonista desses receptores, não impede a ação antitussígena da codeína no gato (14). É possível, então, que os narcóticos atuem também em receptores nãoopioides - talvez de glutamato, serotonina ou nociceptina - no SNC $(17,26)$.

A codeína é um dos antitussígenos mais eficazes, porém comumente provoca efeitos colaterais (náuseas, constipação intestinal) e pode causar dependência (26).

Os antitussígenos de ação central podem potencializar o efeito depressor do SNC do álcool, hipnóticos e sedativos.

\section{Inibidores da bomba protônica}

Em muitos casos de tosse crônica há sintomas ou sinais de refluxo gastroesofágico (RGE), e os inibidores da bomba protônica (IBPs), associados ou não aos procinéticos (bromoprida, domperidona), são comumente prescritos como teste terapêutico. Porém, a metanálise de 18 estudos randomizados e controlados, sendo cinco em crianças e 13 em adultos, indica que não há benefício do uso indiscriminado dos IBPs na tosse crônica (33).

Hunt et al. (2006) (34) avaliaram 22 pacientes adultos com tosse crônica e 22 voluntários sadios quantoà ocorrência de tosse eàs medidas de $\mathrm{pH}$ do vapor condensado do ar exalado na meia hora seguinte à ingestão de limonada. Houve declínio do pH após cerca de 15 minutos, significativamente mais acentuado nos indivíduos com tosse crônica do que nos voluntários.

Os oito pacientes que tossiram no período em que o pH do ar exalado permaneceu abaixo de 7,4 foram os que responderam à terapia feita com IBP durante um mês - os fármacos, doses e posologia não foram especificados. Os pesquisadores sugerem aplicar este método na triagem dos casos de tosse crônica para detectar, de forma não invasiva, a acidificação das VAS por refluxo gastroesofágico, e assim evitar o uso desnecessário de IBPs.

\section{Expectorantes, mucolíticos e outros}

O expectorante guaifenesina é um éter gliceril do guaiacol, resina da planta Guajacum officinlale L., o guaiaco. Esta espécie não deve ser confundida com o guaco (Mikania glomerata Spreng.), cujas folhas são popularmente empregadas no Brasil no preparo de infusão ou decocto para o combate à tosse.

A guaifenesina tem efeito antitussígeno em pacientes com IVAS, mas não inibe o reflexo de tosse em voluntários sadios submetidos à inalação de capsaicina. Seu exato mecanismo de ação não está completamente esclarecido e os efeitos adversos mais frequentes são: cefaleia, náuseas e vômitos.

A vasicina é um alcaloide originalmente isolado das folhas de Adhatodavasica, indicadas pela Ayurveda como expectorante (35). Também as folhas de Sida cordifolia L. (Malvaceae), popularmente conhecida no Brasil como malva-branca, contêm vasicina.

O cloridrato de bromexina é um derivado sintético da vasicina. O mucolítico cloridrato de ambroxol é um metabólito ativo da bromexina e tem propriedades antioxidantes, anti-inflamatórias, surfactante e de anestésico local, a última por bloqueio de canais de sódio. Seus efeitos adversos são: náuseas, vômitos, dor abdominal e erupção cutânea. A superdosagem pode provocar dispneia, ataxia e convulsões (36). O ambroxol não é aprovado pela Food and Drug Administration para uso nos EUA (37).

O iodeto de potássio ainda é encontrado na formulação de alguns expectorantes e seu uso prolongado pode induzir hipotireoidismo.

Estudos clínicos mostram que a monoterapia com nacetilcisteína ou erdosteína não tem efeito antitussígeno, mas os mucolíticos são bons coadjuvantes no tratamento de afecções respiratórias, presumivelmente pelo seu efeito antioxidante (25).

Várias marcas comerciais de antitussígenos isentos de prescrição médica associam a dropropizina, a levodropropizina ou o dextrometorfano com antihistamínicos H1 clássicos (difenidramina, doxilamina) na formulação. Esses anti-histamínicos ajudam a aliviar a tosse graças à sua ação periférica e ao controle da atopia, mas seu efeito no SNC causa sonolência (25).

Nas revisões sistemáticas consultadas não se comprovou que a eficácia da guaifenesina (4), das metilxantinas (teofilina, aminofilina e cafeína) (38), dos anti-histamínicos (39) e do antagonista do receptor de leucotrienos montelucaste $(40,41)$ seja superior à do placebo para alívio da tosse em crianças.

Desde tempos imemoriais o senso comum recomenda o mel de abelha para alívio da tosse seca. O mel é demulcente e contém fenois com ação antioxidante e antimicrobiana. É barato e seguro para uso em crianças maiores de um ano e, se pasteurizado, raramente provoca reação alérgica (42).

Um estudo randomizado comparou o efeito da administração, 30 minutos antes de dormir, de $5 \mathrm{ml}$ de mel ou de dextrometorfano sobre a tosse noturna e a qualidade 
do sono de 105 crianças e adolescentes com IVAS. Um terceiro grupo de pacientes não recebeu tratamento. $\mathrm{O}$ dextrometorfano foi formulado de modo a ter aspecto e sabor semelhantes aos do mel, para que os participantes do estudo não os pudessem distinguir. Os pacientes que utilizaram mel tiveram redução significativa da tosse noturna em comparação com os que não receberam tratamento, benefício não obtido com o dextrometorfano (43).

Outro trabalho randomizado analisou o efeito de uma dose noturna de $2,5 \mathrm{ml}$ de mel, ou de $7,5 \mathrm{mg}$ de dextrometorfano, ou de 6,25 mg de difenidramina, ou de higiene nasal com soro fisiológico sobre a tosse noturna de 139 crianças de dois a cinco anos com IVAS. A frequência e a intensidade da tosse noturna, segundo o relato dos pais, foram significativamente menores no grupo de crianças que usou mel (44).

Apesar desses resultados favoráveis, não há consenso científico sobre a indicação do mel na terapia da tosse aguda em crianças (45).

\section{Terapia Fonoaudiológica na Tosse}

Estima-se que metade dos pacientes com tosse crônica apresente algum grau de disfunção motora das pregas vocais (PPVV), a discinesia laringea, na qual há adução paradoxal involuntária das PPVV durante a inspiração ou expiração (46). A discinesia laríngea pode ser desencadeada por: inalação de irritantes (fumaça ou vapores), baixa temperatura ou umidade excessiva do ar, atos motores que envolvem a musculatura respiratória (exercício físico, fala, riso, inspiração profunda ou deglutição) ou estresse (47). Nesses pacientes a prova de função pulmonar e a oximetria de pulso geralmente são normais, e a tosse é refratária ao tratamento farmacológico com antitussígenos, anti-histamínicos e inibidores da bomba protônica $(46,48)$. O diagnóstico é confirmado através da nasofibrolaringoscopia.

Pesquisadores acompanharam durante dois meses 87 adultos com tosse crônica refratária a medicamentos, sendo $73 \%$ do sexo feminino, divididos aleatoriamente em um grupo controle e outro submetido a sessões individuais de terapia fonoaudiológica (orientações de higiene vocal, exercícios para respiração abdominal e relaxamento voluntário da musculatura laríngea). Eles avaliaram a tosse e a qualidade vocal dos participantes (análise acústica e por eletroglotografia) e constataram melhora significativa de ambas somente no grupo submetido à terapia fonoaudiológica (48).

MurRY e cols. (2010) (47) avaliaram a sensibilidade da mucosa laríngea em 16 adultos com tosse crônica, discinesia laríngea e sintomas de refluxo laringofaríngeo refratários ao tratamento com IBP. A nasofibrolaringoscopia foi feita antes e após três meses de tratamento com IBP administrado duas vezes ao dia (drogas e doses não informados) combinado com retreinamento respiratório (exercícios para aquisição de ritmo respiratório e estímulo à respiração abdominal, feitos durante $10 \mathrm{a} 15$ minutos, duas vezes ao dia). O limiar do reflexo de adução das PPVV foi obtido ao aplicar pulsos de ar comprimido com pressão variável na mucosa da prega ariepiglótica, inervada pelo nervo laríngeo superior, com visualização do movimento de adução das PPVV à nasofibrolaringoscopia. A sensibilidade da mucosa foi significativamente maior ao término do tratamento, e os 12 pacientes que completaram o estudo apresentaram cura da discinesia laríngea e da tosse. Os autores propõem que o edema da mucosa laríngea decorrente do refluxoácido reduziria a sensibilidade dos mecanoceptores vagais, e a tosse e a adução das PPVV seriam respostas adaptativas para defesa das vias aéreas contra aspiração nessa circunstância.

\section{DISCUSSÃO}

A neurofisiologia da tosse é complexa, envolvendo ativação de múltiplos receptores nas vias aéreas e de projeções neurais do núcleo do trato solitário para outras estruturas do sistema nervoso central.

Desvendar a relação fisiopatológica entre a tosse, a acidificação das vias aéreas e a discinesia laríngea é um campo de pesquisa instigante em Laringologia. Estudos recentes anos apontam que muitos pacientes com tosse crônica têm neuropatia sensitiva do nervo laríngeo recorrente, ampliando a compreensão do problema e abrindo a perspectiva de terapêutica com neuromoduladores como a gabapentina e a pregabalina (49-51).

A importância do diagnóstico etiológico da tosse é indiscutível. Contudo, muitos doentes recorrem à automedicação com antitussígenos e mucolíticos - ou solicitam que o médico os prescreva - para atenuar o desconforto até que se identifique a causa do sintoma e se inicie o tratamento específico.

Odextrometorfano e o clobutinol começaram a ser comercializados na década de 1950. Desde então, permanece questionável a vantagem destes antitussígenos em relação ao placebo e têm se sucedido os relatos de efeitos colaterais graves. Portanto, é desejável que as associações brasileiras de especialidades médicas e a Agência Nacional de Vigilância Sanitária, embasadas na literatura científica, orientem os profissionais de saúde e o público leigo e atuem junto aos fabricantes de antitussígenos para 
impedir o uso indiscriminado desses produtos e prevenir intoxicações. Nesse sentido, é conveniente padronizar no País as embalagens de antitussígenos para uso pediátrico, tornando obrigatórios o frasco à prova de abertura pela criança e o copinho dosador.

Apesar dos inúmeros experimentos de neurofarmacologia da tosse ao nível celular e molecular feitos nos últimos anos, a pesquisa clínica de novos antitussígenos mais eficazes e seguros tem sido decepcionante. Os bons resultados obtidos no controle da tosse nos modelos experimentais nem sempre são reproduzidos em humanos, e a inovação mais recente incorporada à prática clínica continua sendo a levodropropizina, lançada na década de 1980.

São necessários mais estudos clínicos duplo-cegos randomizados sobre o benefício do mel de abelha e de outros demulcentes no tratamento da tosse seca. Da mesma forma, pesquisas que mostram o impacto positivo da terapia fonoaudiológica em casos de tosse crônica refratária ao tratamento farmacológico encorajam a realização de protocolos de avaliação laríngea pelo otorrino e fonoaudióloga. Isto confirma a necessidade de atendimento multidisciplinar e multiprofissional aos casos de tosse crônica para assegurar melhor qualidade de vida aos pacientes.

\section{COMENTÁRIOS FINAIS}

Não há evidências de que antitussígenos isentos de prescrição médica tenham eficácia superior à do placebo para o alívio da tosse. Também não está comprovada a eficácia da guaifenesina, das metilxantinas, do montelucaste e dos anti-histamínicos para o tratamento da tosse em crianças.

A terapia fonoaudiológica pode beneficiar pacientes com tosse crônica refratária a o tratamento farmacológico.

\section{AgradeCimentos}

A autora agradece às Sras. Márcia Arruda e Marinalva Aragão pelo auxílio valioso com a bibliografia .

\section{REFERÊNCIAS BIBLIOGRÁFICAS}

1. Fiess E. II Diretrizes brasileiras no manejo da tosse crônica. J Bras Pneumol. 2006, 32 (supl. 6):S403-46.

2. Bouajaoude ZC, Pratter MC. Clinical approach to acute cough. Lung 2010, 188 (suppl. 1):S41-6.
3. Schaefer MK, Shehab N, Cohen AL, Budnitz DS. Adverse events from cough and cough medications in children. Pediatrics. 2008, 121:783-7.

4. Smith SM, Schroeder K, Fahey T. Over-the-counter medications for acute cough in children and adults in ambulatory settings. Cochrane Database Syst Rev. 2008: (1):CD001831.

5. Shefrin AE, Goldman RD. Use of over-the-counter cough and cold medications in children. Can Family Phys 2009; 55: 1081-3.

6. Boehringer Ingelheim. Retirada do mercado do Cloridrato de Clobutinol (Silomat ${ }^{\circledR}$ e Silomat ${ }^{\circledR}$ Plus). [2007] Encontrado em URL: http://portal.anvisa.gov.br/wps/wcm/connect/ 96a21d804237610cbd70fd01cce3dc94Carta +da+ empresa+Boehringer+Ingelheim + sobre $+\mathrm{a}+$ retirada $+\mathrm{do}+$ mercado + dos + medicamentos + Silomat $\% \mathrm{C} 2 \% \mathrm{AE}+$ e+Silomat\%C2\%AE+Plus_.pdf?MOD=AJPERES.

7. Reis AMM, Figueras A. Analysis of the evidence of efficacy and safety of over-the-counter cough medications registered in Brazil. Braz J Pharm Sci. 2010, 46:135-45.

8. Gupta D, Verma S, Vishwakarma SK. Anatomic basis of Arnold's ear-cough reflex. Surg Radiol Anat. 1986, 8: 21720.

9. Tekdemir I, Aslan A, Elhan A. A clinico-anatomic study of the auricular branch of the vagus nerve and Arnold's earcough reflex. Surg Radiol Anat. 1998, 20:253-7.

10. Undem BJ, Carr MJ. Targeting primary afferent nerves for novel antitussive therapy. Chest. 2010, 137:177-84.

11. Kollarik M, Ru F, Undem BJ. Acid-sensitive vagal sensory pathways and cough. Pulm Pharmacol Ther. 2007, 20:40211.

12. Hamamoto T, Takumida M, Hirakawa K, Takeno S, Tatsukawa T. Localization of transient receptor channel vanilloid subfamilies in the mouse larynx. Acta Otolaryngol. 2008, 128:685-93.

13. Geppetti P, Pattachine R, Nassini R, Materazzi S. Cough: the emerging role of tge TRPA-1 channel. Lung. 2010, 188(suppl.1):S63-8.

14. Takahama K, Shirasaki T. Central and peripheral mechanisms of narcotic antitussives: codeine-sensitive and - resistant coughs. Cough. 2007, 3:8.

15. Plevkova J, AntosiewiczJ, Varechova S, Poliacek I, Jakus $\mathrm{J}$, Tatar M et al. Convergence of nasal and tracheal neural 
pathways in modulating the cough response in Guinea pigs. J Physiol Pharmacol. 2009, 60:89-93.

16. Mazzone SB, Mori N, Canning BJ. Synergistic interactions between airway afferent nerve subtypes regulating the cough reflex in guinea pigs. J Physiol. 2005, 569:559-73.

17. Canning BJ. Central regulation of the cough reflex: therapeutic implications. Pulm Pharmacol Ther. 2009, 22:7581.

18. Canning BJ. Encoding the cough reflex. Pulm Pharmacol Ther. 2007, 20:396-401.

19. Veras TN, Pinto LA. Tosse psicogênica em criança: relato de caso. Sci Med. 2008, 18:54-7.

20. Thach BT. Maturation of cough and other reflexes that protect the fetal and neonatal airway. Pulm Pharmacol Ther. 2007, 20:365-70.

21. Dragomir A, Akay Y, Curran AK, Akay M. Investigating the complexity of respiratory patterns during the laryngeal chemoreflex. J Neuroeng Rehab. 2008, 5:17.

22. Dicpinigaitis PV. Experimentally induced cough. Pulm Pharmacol Ther. 2007, 20:319-24.

23. Sitkauskiene B, Dicpinigaitis PV. Effect of smoking on cough reflex sensitivity in humans. Lung. 2010, 188(suppl.1):S29-32.

24. Morice AH. The cough hypersensitivity syndrome: a novel paradygm for understanding cough. Lung. 2010, 188 (suppl.1):S87-90.

25. Bolser DC. Pharmacologic management of cough. Otolaryngol Clin North Am. 2010, 43:147-55.

26. Minamizawa K, Goto H, Ohi Y, Shimada Y, Terasawa K, Haji A. Effect of d-pseudoephdrine on cough reflex and its mode of action in Guinea pigs. J Pharmacol Sci. 2006, 102:136-42.

27. Leconte S, Ferrant D, Dory V, Degryse J. Validated Methods of Cough Assessment: A Systematic Review of the Literature. Respiration. 2010, DOI: 10.1159/000321231.

28. Schönffeldt PG, Céspedes JG, Sepúlveda R, Salamanca ME. Aumento del umbral tusígeno en sujetos sanos con el uso de levodropropizina. Rev Chil Enf Respir. 2005, 21:16570 .

29. Mutschler J, Koopmann A, Grosshans M, Hermann D, Mann K, Kiefer F. Dextromethorphan withdrawal and dependence syndrome. Dtsch Arztebl Int. 2010, 107:53740.

20. Rimsza ME, Newberry S. Unexpected Infant Deaths Associated With Use of Cough and Cold Medications. Pediatrics. 2008, 122:e318.

31. Takahara A, Sasaki R, Nakamura M, Sendo A, Sakurai Y, Namekata I et al. Clobutinol delays ventricular repolarization in the guinea pig heart: comparison with cardiac effects of HERG K+ channel inhibitor E-4031. J Cardiovasc Pharmacol. 2009, 54:552-9.

32. Seitz CS, Bröcker EB, Trautmann A. Allergy evaluation after emergency treatment: anaphylaxis to the over-thecounter medication clobutinol.Emerg Med J. 2007, 24:e19.

33. Chang AB, Lasserson TJ, Gaffney J, Connor FL, Garske LA. Gastro-oesophageal reflux treatment for prolonged nonspecific cough in children and adults. Cochrane Database Syst Rev. 2005, (2):CD004823.

34. Hunt J, Yu Y, Burns J, Gaston B, Ngamtrakulpanit L, Bunyan D et al. Identification of acid reflux cough using serial assays of exhaled breath condensate pH. Cough. 2006, 2:3.

35. Soni S, Anandjiwala S, Patel G, Rajani M. Validation of Different Methods of Preparation of Adhatoda vasica Leaf Juice by Quantification of Total Alkaloids and Vasicine. Indian J Pharm Sci. 2008, 70(1):36-42.

36. Gupta PR. Ambroxol - Resurgence of an old molecule as an anti-inflammatory agent in chronic obstructive airway diseases. Lung India. 2010, 27:46-8.

37. Chang CYC, Sachs HC, Lee CE. Unexpected Infant Deaths Associated With Use of Cough andCold Medications [carta]. Pediatrics. 2009, 123:2:e359.

38. Chang AB, Halstead RA, Petsky HL. Methylxanthines for prolonged non-specific cough in children. Cochrane Database Syst Rev. 2005, (3):CD005310.

39. Chang AB, Peake J, McElrea MS. Anti-histamines for prolonged non-specific cough in children. Cochrane Database Syst Rev. 2008, 2:CD005604.

40. Chang AB, Winter D, Acworth JP. Leukotriene receptor antagonist for prolonged non-specific cough in children. Cochrane Database Syst Rev. 2006, 2:CD005602.

41. Chang CC, Cheng AC, Chang AB Over-the-counter(OTC) medications to reduce cough as an adjunct to antibiotics for acute pneumonia in children and adults. Cochrane Database Syst Rev. 2007, (4):CD006088. 
42. Warren MD, Pont SJ, Barkin SL, Callahan ST, Caples TL, Carroll KN et al. The effect of honey on nocturnal cough and sleep quality for vhildren and their parents. Arch Pediatr Adolesc Med. 2007, 161:1149-53.

43. Paul IM, Beiler J, McMonagle A, Shaffer ML, Duda L, Berlin Jr. CM. Arch Pediatr Adolesc Med. 2007, 161:11406.

44. Shadkam MN, Mozaffari-Khosravi H, Mozayan MR. A comparison of the effect of honey, dextromethorphan, and diphenhydramine on night coughand sleep quality in children and their parents. J Altern Compl Med. 2010, 787-93.

45. Oduwole O, Meremikwu MM, Oyo-Ita A, Udoh EE. Honey for acute cough in children. Cochrane Database Syst Rev. 2010, 1:CD007094.

46. Vertigan AE, Theodoros DG, Gibson PG, Winkworth AL. Efficacy of speech pathology management for chronic cough: a randomised placebo controlled trial of treatment efficacy. Thorax. 2006, 61:1055-69.
47. Murry T, Branski CK, Yu K, Cukier-Blaj S, Duflo S, Aviv JE. Laryngeal sensory deficits in patients with chronic cough and paradoxical vocal fold movement disorder. Laryngoscope. 2010, 120:1576-81.

48. Gibson PG, Vertigan AE. Speech pathology for chronic cough: a new approach. Pulm Pharmacol Ther. 2009, 22:159-62.

49. Lee JK, Mintz S. Chronic cough as a sign of laryngeal sensory neuropathy: diagnosis and treatment. Ann Otol Rhinol Laryngol. 2006, 115:871.

50. Halum SL, Sycamore DL, McRae BR. A new treatment option for laryngeal sensory neuropathy. Laryngoscope. 2009, 119:1844-7.

51. Norris BK, Schweinfurth JM. Management of recurrent laryngeal sensory neuropathic symptoms. Ann Otol Rhinol Laryngol. 2010, 119:188-91. 